\title{
Smoke Alarm Maintenance in an Australian Community Sample
}

\author{
MICHELLE BARNETT ${ }^{2}$, DOROTHY BRUCK ${ }^{1,2}$, and MICHELLE BALL ${ }^{1,2}$ \\ ${ }^{1}$ School of Social Sciences and Psychology \\ Victoria University \\ PO Box 14428, Melbourne 8001, Australia \\ ${ }^{2}$ Centre for Environmental Safety and Risk Engineering \\ Victoria University \\ PO Box 14428, Melbourne 8001, Australia
}

\begin{abstract}
Australia has a high rate of smoke alarm ownership, with compulsory installation requirements across all states. Although this is pleasing, it is not correct to assume that a smoke alarm will be in functional order without appropriate maintenance. Procedures to optimise smoke alarm performance include yearly replacement of the battery, and monthly testing of the alarm sounder and cleaning of the unit with a vacuum cleaner. The current study interviewed 500 people randomly selected from shopping centres in Melbourne, Australia, about the maintenance of their smoke alarm. Overall it was found that $17 \%$ of people reported never changing the battery. Most people who reported never changing their smoke alarm battery owned hardwired alarms. Only $57 \%$ reported cleaning their alarms, and of these, $75 \%$ did so less often than recommended. Lower numbers still reported cleaning their smoke alarm (21\%), and only $15 \%$ of these people reported following the correct cleaning procedure. Implications are discussed in relation to targeting community information campaigns.
\end{abstract}

KEYWORDS: alarm, smoke detectors, smoke alarms, maintenance, human behaviour.

\section{INTRODUCTION}

There are a number of risk reduction activities that are generally promoted to the public in relation to smoke alarm requirements. The first is the installation of the device(s), with the correct number of alarms and correct placement of alarms in the home. The second involves maintenance actions to reduce risk, including the periodic testing of alarms, cleaning of alarms, and changing the alarm batteries. The strategies used to encourage such actions include the local law and reminders to test detectors and replace batteries [1]. Such strategies are conveyed to the public through public information and education campaigns that are usually conducted by fire departments, hospital burns units, health departments, and other agencies [1].

\section{Maintenance of Smoke Alarms}

Smoke alarm regulations state that the alarms must be in functional order. It is not simply enough to have installed a smoke alarm, of course it must be in proper working order [2]. To promote functionality, it is important that smoke alarms undergo regular maintenance. There are three important maintenance routines required: testing the alarm, changing batteries, and cleaning the alarm [3]. Although regular maintenance is demanded, regulations do not stipulate how to carry this out. Of the three routines, the emphasis is given to the yearly replacement of alarm batteries, while testing and cleaning are not given the same widespread exposure.

The occupant of a dwelling is responsible for the regular testing of any smoke alarms that are present. Recommendations regarding the frequency of testing vary among jurisdictions. It is recommended that they should be tested each week to ensure the battery and sounder are in working order by the Melbourne Metropolitan Fire Brigade [3], but more commonly the time frame recommended is monthly. This is a very simple procedure that requires the test button to be pressed, which triggers the alarm if all is in working order. Alternatively, smoke alarms can be tested by using artificial smoke, which is commercially available in an aerosol can.

Much less effort is required to maintain the battery of a smoke alarm, with recommendations stating that it should be changed yearly. This recommendation applies to the most commonly used 9 volt (V) batteries. In Australia, public information campaigns are used to remind people to change their smoke alarm batteries when they change their clocks, at the commencement or end of daylight savings time [3]. Should the 
battery be depleted in less than one year, the sounder will usually emit an intermittent alerting signal [2]. In contrast to $9 \mathrm{~V}$ batteries, lithium batteries are also available, and can power smoke alarms for about 7 to 10 years. Since it is recommended that smoke alarm units be replaced each 10 years, this time span may cover the lifetime of the unit [4]. Annual replacement is also required for the back-up batteries that are fitted in hard-wired smoke alarms [5]. In Australia, the responsibility for the annual replacement of batteries in smoke alarms is the owner in owner occupied dwellings, and in rental properties, the landlord.

In addition to regular testing, and annual battery changes, smoke alarms should be cleaned monthly with a vacuum cleaner to remove dust build up that might affect smoke alarm performance [5].

\section{Does Owning a Smoke Alarm Mean it is in Working Order?}

Although results from surveys show quite high smoke alarm prevalence rates in the USA and Australia, the presence of a smoke alarm does not necessarily mean that it is in working order. A number of studies have conducted home inspections to physically test alarms to determine their working status, or have requested participants to test their alarm while on the phone (preceding a telephone interview). Most of these studies have found that although occupants may have smoke alarms installed, a substantial percentage of these are not in working order.

For example, in 1985 the Center of Disease Control (CDC) conducted a random digit dialing telephone survey in DeKalb County Georgia, United States, which was followed by a home inspection, in order to determine smoke alarm ownership and functionality [6]. Interviews were conducted with 435 occupants in private residencies Results from the survey indicated that reported smoke alarm ownership was $76.3 \%$, with nearly $5 \%(15 / 332)$ of these owned detectors reportedly not yet installed. The home inspection follow up was conducted with $10.6 \%$ of the original respondents. Results from the inspections uncovered that nearly $30 \%$ of owners had non-functioning smoke detectors, despite having reported an installed detector in their home.

In 1992 Neily, Smith and Shapiro [7] found similar results to the CDC when they conducted in-home interviews followed by alarm testing. The smoke detector operability survey was carried out with 1012 households from October 1 to December 23, 1992. A sample of 40 USA postal zip codes was used for interviewing respondents in a primary sample, and in a sample of lower socio-economic status households. In addition to the interview information gathered, the researchers tested each smoke detector with standard aerosol smoke and with the test button. Results revealed the $88 \%$ of households had one or more smoke detectors, but when these alarms were tested only $75 \%$ of installed detectors responded, meaning that $25 \%$ of smoke alarms were found to be inoperable. The picture was even worse in a 1999 study by Douglas, Mallonee, and Istre [8], who discovered a $17 \%$ disparity between reported and tested functional status in their household survey of 1413 randomly selected one and two family homes in August 1990. Results from the household survey showed that $66 \%$ of occupants reported having functioning alarms, but this number dropped to $49 \%$ when the alarms were tested. Finally, in 1992 Sharp and Carter [9] also uncovered inconsistency between number of alarms and number of working alarms in their study to measure the prevalence of smoke detectors among welfare recipients. One hundred and nine black women residing in inner-city Memphis, who were receiving aid for families with dependent children, were interviewed and their homes were inspected for functional smoke detectors. Forty of the 109 homes $(36.7 \%)$ had no smoke detectors installed. Of the 69 smoke detectors tested $17.4 \%$ did not work. According to the authors, respondents who said they had checked their detectors to see if they worked were significantly more likely to have functional smoke detectors, and 95 percent of participants with detectors were able to check them correctly. Overall these studies found prevalence rates of between $66 \%$ and $88 \%$ homes that reported having smoke alarms, but that startling proportion of smoke alarms were not functional (17-30\%).

\section{Reasons for Non-functioning Alarms}

Research studies typically show that the most common reasons why smoke alarms are not in working order is because the batteries are either missing, flat, or have been disconnected. Maintenance problems have been found in studies as early as 1985, for example McLoughlin, Marchone, Hanger, German, and Baker found that of 651 households inspected, in which there were 1028 smoke detectors, 863 (84\%) sounded an alarm when tested. Among the battery powered detectors which were not functional $32 \%$ had no batteries, $51 \%$ had dead batteries and $17 \%$ had other problems [10]. 
A number of studies have investigated the reasons for non-functioning alarms in homes with occupants of a low socio-economic status. For instance, Mickalide and Validzic [11] investigated the effectiveness of smoke alarm installation in low income homes across the USA. In keeping with the results reported above, the authors found that $17 \%$ of the 500 devices they tested were non-functional, and that most of these had missing or dead batteries, or had been disabled in other ways. There were no cases found in which the alarm was malfunctioning because of dirt/dust or insects. The follow up testing of alarms in this study was conducted only a short time after installation (6 months), and a substantial number were already not in working order. This number could only be expected to grow with time as malfunction due to dust build up became more likely. The importance of placing smoke alarms where nuisance activations are minimised to prevent battery disablement was highlighted.

Another study also investigated the long term functional status of smoke detectors distributed to high-risk households in eight areas of Minnesota, Cherokee County (North Carolina) and Oklahoma City (Oklahoma) [12]. Home visits in this study were conducted to check smoke alarms that were distributed 3 to 4 years previously. As expected, the increased period of time between installation and the home visit meant an even greater number of alarms were found to be non-functional. The percentage of evaluation households with at least one working detector ranged from $58 \%$ in Oklahoma to $73 \%$ in North Carolina. Overall, $73 \%$ of non-functional alarms had batteries that were either missing or disconnected. When the researchers replaced the batteries of these alarms, $83 \%$ regained function. The authors concluded that future programs should consider distributing detectors that do not require yearly battery changes, or find more effective ways to ensure the batteries are routinely replaced.

This conclusion has been substantiated in other studies. Neily, Smith, and Shapiro found that $80 \%$ of nonfunctional smoke alarms had no functioning power source [7]. Twenty-five percent had dead batteries, and almost $75 \%$ had missing or disconnected batteries, or were disconnected from AC power supply. When the authors asked the owners why their smoke alarms had no power, nearly half reported that they either forgot to replace the battery, or did not know why the battery or power supply was missing or disconnected. Contrary to what is popularly believed, only a small number $(5 \%)$ of smoke alarms were disconnected from their power source due to nuisance alarms. This was also found by Sharp and Carter whose results showed that detector location and the occurrence of false alarms while cooking were not related to smoke alarm working status [9]. These authors reported a relatively high proportion of smoke alarms with battery problems, and suggested that programs to encourage battery replacement are needed.

\section{The Occurrence of Nuisance Alarms}

As previously mentioned above Neily, Smith, and Shapiro reported that only $5 \%$ of smoke alarms in their study were disconnected due to nuisance alarms [7]. Despite this, false alarms were found to be a common occurrence. Fifty-one percent of their sample reported to have experienced alarms when there was no fire. The most common reason reported for these false alarms was cooking $(80 \%)$, followed by low batteries $(20 \%)$, and steam from bathrooms (6\%). It is interesting to note that $20 \%$ of false alarm reports were said to be due to low batteries. It is of concern that a high number of people misinterpreted the low battery signal or 'chirp' as a nuisance alarm, instead of as a warning to replace the power source, and may go some way towards explaining the high prevalence of smoke alarms that are not functional due to this reason.

Similarly, a substantial number of false alarm experiences were found in a 2004 survey conducted for the NFPA. Results showed that $40 \%$ of respondents with smoke alarms reported that one had sounded at least once in the past 12 months [13]. Reasons for the false activations were similar the previous study; cooking $(69 \%)$ battery problems $(13 \%)$, and steam $(5 \%)$. Although false alarms do not feature highly as a reason for the disablement or removal of power sources, they remain of concern as they risk increasing complacency, which is a less than desirable attitude towards a device that is designed to warn of potentially life-threatening danger.

\section{Hardwired vs. Battery Operated}

Research indicates that hardwired smoke alarms are more likely to be working than battery operated alarms when in-home testing is conducted. For example, Neily, Smith and Shapiro found $84 \%$ of AC powered alarms were functional, compared to $69 \%$ of battery powered alarms [7]. 
In 1985 McLoughlin, Marchone, Hanger, German, and Baker found similar results as $81 \%$ of 791 battery powered detectors were in working order, while $92 \%$ of 237 wired detectors were working [10]. These authors used their results to assert that building codes should require that detectors be wired into the household current.

Although hardwired alarms are more likely to be working, the alarm may still become non-functional if normal maintenance procedures are not followed The NFPA caution that even hard wired alarm batteries must be replaced in accordance to manufacturer's instructions, which is usually annually [14]. They also support the use of the 10 year extended life lithium battery operated device mentioned earlier.

According to the NFPA most residential dwellings in the US have battery powered smoke alarms that are not interconnected. In Australia, estimates from a survey conducted by the Australian Bureau of Statistics (ABS) in October 1996 also showed that the vast majority of smoke alarms were battery operated $(92.3 \%)$ [15].

\section{Aim}

Although there is ample evidence from overseas studies that smoke alarm maintenance procedures are generally not well adhered to, no Australian data currently exists. The current study aims to determine whether correct and regular maintenance behaviours are being carried out by Australian residents who own a smoke alarm.

\section{METHOD}

Five hundred participants, recruited from four shopping centres located in Melbourne, Victoria were interviewed as a part of a larger study. Of the 500, a total of 477 gave information about smoke alarms. Seven items of the larger study pertained to smoke alarms and their maintenance, and it is that material which is examined here. A descriptive analysis was conducted using the collected data to investigate maintenance behaviours for smoke alarms across different demographics.

\section{RESULTS}

Of the 500 respondents, 477 reported having a smoke alarm (95.4\%). When age was considered, all occupants aged 59 years and over reported owning smoke alarms. No other factors were related to age.

\section{Smoke Alarm Maintenance}

The following data summarises responses to questions regarding smoke alarm maintenance, including battery changes, testing, and cleaning.

Table 1. Frequency statistics for smoke alarm maintenance: battery changes $(n=477)$.

\begin{tabular}{lrr}
\hline \multicolumn{1}{c}{ Variable } & n & \% \\
\hline Change battery? & & \\
Yes & 371 & 77.8 \\
No & 80 & 16.8 \\
Just moved in (not needed to yet) & 6 & 1.2 \\
Unsure & 19 & 4.0 \\
Unknown & 1 & $<1$ \\
If yes how often $(\mathbf{n}=\mathbf{3 7 1})$ & & \\
When it beeps & 101 & 27.2 \\
Every month & 8 & 2.1 \\
Every 6 months & 80 & 21.6 \\
Once a year & 174 & 46.9 \\
Irregularly & 8 & 2.1 \\
\hline
\end{tabular}

Table 1 shows that over three quarters of people who own a smoke alarm stated that they change the batteries in their smoke alarm, whereas about $17 \%$ stated that they do not. About $30 \%$ of people who 
reported changing the batteries in their smoke alarm said they performed this procedure less often than recommended.

The following figure shows the proportions of people who reported that they did not change the battery in their smoke alarm by the type of alarm they owned.

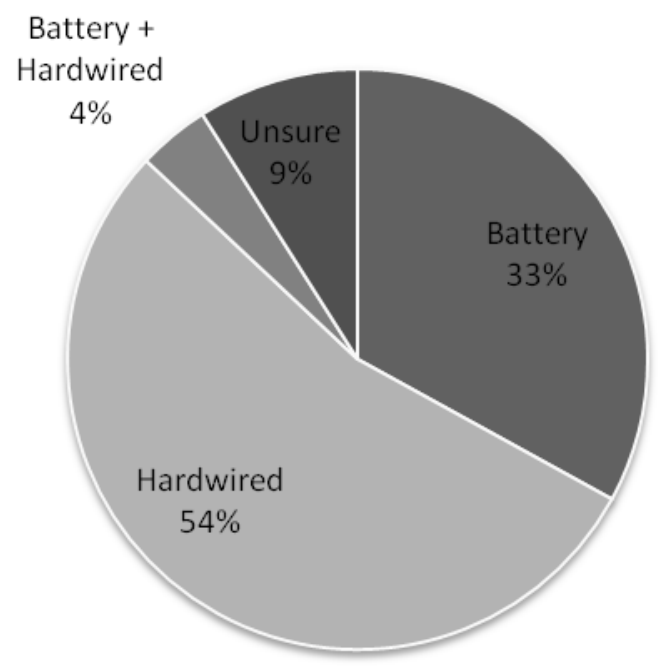

Fig. 1. Type of alarm owned by occupants who do not change their batteries.

Figure 1 shows that of 80 participants who report never changing their alarm batteries, over half owned hardwired detectors and around a third owned battery operated detectors.

Table 2. Frequency statistics: testing the alarm $(n=477)$.

\begin{tabular}{lrr}
\hline Variable & $\mathbf{n}$ & \% \\
\hline Test alarm & 274 & 57.4 \\
Yes & 166 & 34.8 \\
No & 3 & $<1$ \\
Just moved in (not needed to yet) & 19 & 4.0 \\
Unsure & 15 & 3.2 \\
Unknown & & \\
If yes how often $(\mathbf{n}=\mathbf{2 7 4})$ & 1 & $<1$ \\
Daily & 12 & 4.4 \\
Weekly & 58 & 21.2 \\
Every month & 68 & 24.8 \\
Every 6 months & 59 & 21.5 \\
Once a year & 76 & 27.7 \\
Irregularly & & \\
If yes testing method $(\mathbf{n}=\mathbf{2 7 4})$ & 213 & 77.7 \\
Press button & 11 & 4.0 \\
Burnt toast/cooking & 6 & 2.2 \\
Lighter/match & 1 & $<1$ \\
Artificial smoke & 6 & 2.2 \\
Other & 3 & 1.1 \\
Unsure & 34 & 12.4 \\
Unknown & & \\
\hline
\end{tabular}

Table 2 shows over half of those owning smoke alarms stated that they test the devices, but more than one in four of these people do so only irregularly. The majority of participants reported testing their alarm by 
pressing the button on the device. Disturbingly, a small proportion of people believe that the alarm is 'tested' when it sounds due to cooking.

Table 3. Frequency statistics: cleaning $(n=477)$.

\begin{tabular}{lrr}
\hline Variable & $\mathbf{n}$ & \% \\
\hline Clean alarm & 122 & 25.6 \\
Yes & 316 & 66.2 \\
No & 5 & 1.0 \\
Just moved in (not needed to yet) & 26 & 5.5 \\
Unsure & 8 & 1.7 \\
Unknown & & \\
If yes how often $(\mathbf{n}=\mathbf{1 2 2})$ & 8 & 6.6 \\
Weekly & 20 & 16.4 \\
Every month & 1 & $<1$ \\
Every 4 months & 20 & 16.4 \\
Every 6 months & 33 & 27.0 \\
Once a year & 40 & 32.8 \\
Irregularly & & \\
If yes cleaning method (n=122) & 31 & 25.4 \\
Dust or wipe inside & 66 & 54.1 \\
Dust or wipe outside & 18 & 14.8 \\
Vacuum & 1 & $<1$ \\
Soap and water & 6 & 4.9 \\
Unknown &
\end{tabular}

Table 3 shows that the majority of participants stated that they do not clean their smoke alarms. Of those who do the most popular cleaning method was to wipe or dust the outside of the alarm.

\section{Demographics and Smoke Alarm Maintenance}

The following data summarises responses according to demographic characteristics of respondents including maximum education, and employment status.

Table 4. Smoke alarm owner demographics and battery changing behaviours.

\begin{tabular}{|c|c|c|c|c|c|c|c|c|c|}
\hline \multirow{3}{*}{$\begin{array}{l}\text { Variable } \\
\text { Maximum education }\end{array}$} & \multicolumn{9}{|c|}{ Reported frequency of battery changes } \\
\hline & \multirow{2}{*}{$\begin{array}{r}N \\
444\end{array}$} & \multicolumn{2}{|c|}{$\begin{array}{c}\text { Yearly or } \\
\text { sooner }\end{array}$} & \multicolumn{2}{|c|}{ Beeps } & \multicolumn{2}{|c|}{ Irregularly } & \multicolumn{2}{|c|}{ Never } \\
\hline & & $\mathrm{n}$ & $\%$ & $\mathrm{n}$ & $\%$ & $\mathrm{n}$ & $\%$ & $\mathrm{n}$ & $\%$ \\
\hline Year 11 or below & 174 & 109 & 62.6 & 30 & 17.2 & 4 & 2.3 & 31 & 17.8 \\
\hline Year 12 completed & 72 & 37 & 51.4 & 22 & 30.6 & 1 & 1.4 & 12 & 16.7 \\
\hline TAFE $^{\mathrm{a}}$ & 66 & 38 & 57.6 & 14 & 21.2 & 1 & 1.5 & 13 & 19.7 \\
\hline University & 118 & 27 & 22.9 & 70 & 59.3 & 0 & 0 & 21 & 17.8 \\
\hline Apprentice & 14 & 6 & 46.1 & 6 & 46.1 & 1 & 7.6 & 1 & 7.6 \\
\hline Employment status & 439 & & & & & & & & \\
\hline Employed & 259 & 149 & 57.5 & 69 & 26.6 & 3 & 1.1 & 38 & 14.7 \\
\hline Not employed & 39 & 24 & 61.5 & 3 & 7.7 & 1 & 2.6 & 11 & 28.2 \\
\hline Not in labour force & & & & & & & & & \\
\hline Retired & 84 & 45 & 53.6 & 22 & 26.2 & 3 & 3.6 & 14 & 16.7 \\
\hline Stay home parent & 39 & 27 & 69.2 & 4 & 10.3 & 0 & 0 & 8 & 20.5 \\
\hline Student & 18 & 10 & 55.6 & 2 & 11.1 & 0 & 0 & 6 & 33.3 \\
\hline
\end{tabular}

${ }^{\mathrm{a}}$ TAFE - Technical and Further Education (Trades) 
Table 4 shows that a higher proportion of students and unemployed persons reported never changing their smoke alarm battery, compared to the employed, stay at home parents, and the retired. However overall numbers in these two groups are very small, particularly for the students, so this must be interpreted with caution. Across the different levels of education the results were largely very consistent, with around 17 to $20 \%$ of all groups stating they never change the battery. (The exception was apprentices with only $7.6 \%$, but numbers from this group were very small). Noteworthy is that, contrary to recommendations, a surprising proportion of people with a university qualification wait until their smoke alarm beeps to replace the battery.

Table 5. Frequency statistics of smoke alarm owner demographics and testing behaviours

\begin{tabular}{|c|c|c|c|c|c|c|c|c|c|c|c|}
\hline \multicolumn{12}{|c|}{ Reported frequency of testing } \\
\hline \multirow{2}{*}{$\begin{array}{l}\text { Variable } \\
\text { Maximum education }\end{array}$} & \multirow{2}{*}{$\frac{N}{434}$} & \multicolumn{2}{|c|}{$\begin{array}{c}\text { Weekly or } \\
\text { sooner }\end{array}$} & \multicolumn{2}{|c|}{$\begin{array}{l}\text { Monthly to } \\
\text { six monthly }\end{array}$} & \multicolumn{2}{|c|}{ Yearly } & \multicolumn{2}{|c|}{ Irregularly } & \multicolumn{2}{|c|}{ Never } \\
\hline & & $\mathrm{n}$ & $\%$ & $\mathrm{n}$ & $\%$ & $\mathrm{n}$ & $\%$ & $\mathrm{n}$ & $\%$ & $\mathrm{n}$ & $\%$ \\
\hline Year 11 or below & 173 & 8 & 4.6 & 45 & 26.0 & 16 & 9.3 & 39 & 22.5 & 65 & 37.6 \\
\hline Year 12 completed & 72 & 1 & 1.4 & 21 & 29.2 & 9 & 12.5 & 17 & 23.6 & 24 & 33.3 \\
\hline TAFE $^{\mathrm{a}}$ & 62 & 0 & 0 & 23 & 37.1 & 12 & 19.4 & 7 & 11.3 & 20 & 32.3 \\
\hline University & 111 & 3 & 2.7 & 33 & 29.7 & 20 & 18.0 & 12 & 10.8 & 43 & 38.7 \\
\hline Apprentice & 16 & 1 & 6.3 & 2 & 12.5 & 1 & 6.3 & 1 & 6.3 & 11 & 68.8 \\
\hline Employment status & 428 & & & & & & & & & & \\
\hline Employed & 256 & 2 & $<1$ & 80 & 31.3 & 35 & 13.7 & 39 & 15.2 & 100 & 39.0 \\
\hline $\begin{array}{l}\text { Not employed } \\
\text { Not in labour force }\end{array}$ & 38 & 2 & 5.3 & 8 & 21.1 & 4 & 10.5 & 6 & 15.8 & 18 & 47.4 \\
\hline Retired & 81 & 6 & 7.4 & 18 & 22.2 & 11 & 13.6 & 20 & 24.7 & 26 & 32.1 \\
\hline Stay home parent & 39 & 1 & 2.6 & 12 & 30.8 & 7 & 18.0 & 6 & 15.4 & 13 & 33.3 \\
\hline Student & 14 & 0 & 0 & 3 & 21.4 & 2 & 14.3 & 3 & 21.4 & 6 & 42.9 \\
\hline
\end{tabular}

${ }^{\mathrm{a}}$ TAFE - Technical and Further Education (Trades)

Table 5 shows that the number of persons who reported never testing their smoke alarms is reasonably high across all groups in terms of employment status. It seems about one in three people never test their smoke alarm, and this rate jumps to one in two for the unemployed. Similar results are seen across the different levels of education, with about one in three people reporting that they never test their smoke alarm. A possible exception is that the rate jumps to two in three for apprentices, however they are a small group in this study, so this should once again be interpreted with caution.

Table 6. Frequency of smoke alarm owner demographics and cleaning behaviours.

\begin{tabular}{l|r|rrrrrrrr}
\hline \multicolumn{8}{|c}{} & \multicolumn{8}{c}{ Reported frequency of cleaning } \\
\hline Variable & $\mathbf{N}$ & \multicolumn{2}{c}{$\begin{array}{c}\text { Weekly or } \\
\text { sooner }\end{array}$} & \multicolumn{2}{c}{$\begin{array}{c}\text { 6 months } \\
\text { to yearly }\end{array}$} & \multicolumn{2}{c}{ Irregularly } & \multicolumn{2}{c}{ Never } \\
\hline Maximum education & $\mathbf{4 2 7}$ & $\mathrm{n}$ & $\%$ & $\mathrm{n}$ & $\%$ & $\mathrm{n}$ & $\%$ & $\mathrm{n}$ & $\%$ \\
Year 11 or below & 168 & 17 & 10.1 & 22 & 13.1 & 20 & 11.9 & 109 & 64.9 \\
Year 12 completed & 72 & 5 & 6.9 & 6 & 8.3 & 7 & 9.7 & 54 & 75.0 \\
TAFE $^{\mathrm{a}}$ & 61 & 2 & 3.3 & 8 & 13.1 & 3 & 4.9 & 48 & 78.7 \\
University $_{\text {Apprentice }}^{112}$ & 4 & 3.5 & 13 & 11.6 & 10 & 8.9 & 85 & 75.9 \\
Employment status & 15 & 0 & 0 & 1 & 6.7 & 0 & 0 & 14 & 93.3 \\
Employed & $\mathbf{4 3 9}$ & & & & & & & & \\
Not employed & 252 & 15 & 59.5 & 37 & 14.7 & 26 & 10.3 & 174 & 69.0 \\
Not in labor force & 40 & 5 & 12.5 & 3 & 7.5 & 6 & 15.0 & 26 & 65.0 \\
Retired & & & & & & & & & \\
Stay home parent & 81 & 4 & 4.9 & 8 & 9.9 & 6 & 7.4 & 63 & 77.8 \\
Student & 38 & 4 & 10.5 & 5 & 13.2 & 1 & 2.6 & 28 & 73.7 \\
& 16 & 0 & 0 & 0 & 0 & 1 & 6.3 & 15 & 93.8 \\
\hline
\end{tabular}

${ }^{a}$ TAFE - Technical and Further Education (Trades) 
Table 6 shows that across all groups (for both education level and employment status) the largest proportion of smoke alarm owners never clean their smoke alarms.

\section{DISCUSSION}

\section{Battery Replacement}

Of 80 occupants who reportedly never change their alarm batteries (Table 1), most were those who own hardwired alarms (58\% had some hardwiring) compared to those who own battery operated alarms (33\%). When these people were asked why, the majority stated that they did not need to change the battery because the alarm is hardwired. Another participant stated that he did not need to change the battery because his dogs would alert him in the event of a fire. One person reported that the local fire service changed the smoke alarm battery in her home. This indicates that a disturbing number of occupants with hardwired alarms may not be aware of the need to replace the batteries in their smoke alarms on a regular basis.

Previous studies have shown that hardwired detectors are more likely to be working than battery powered detectors upon testing, but they are not always found to be in working order e.g. Refs [7,14]. This has particular implications for occupants living in new homes with hardwired smoke alarms who may be ignorant of the fact that these units also need battery replacements (Australian Standards require that smoke alarms that are hardwired have a backup battery). This becomes even more important if we consider that the use of hardwired alarms seems to be increasing. In October 1996 the Australian Bureau of Statistics showed the vast majority of smoke alarms were battery operated (92.3\%) [15]. The current results show a change in this trend, with an increase in the proportion of hardwired alarms (Fig. 1). Here, most occupants still reported owning battery operated smoke alarms $(72.4 \%)$, but this represents a drop of some $20 \%$. The next most commonly reported type of smoke alarm was hardwired (15.5\%), followed by both battery and hardwired $(8.6 \%)$. This is disturbing because the above results indicate that over half of these people are unaware of the need to change the battery in these alarms, which means that they may fail to sound in response to a real fire emergency.

\section{Testing of Alarms}

Results from the current study (Table 2) show that although a high percentage of occupants report owning a smoke alarm, about one third of people are not testing them (34.8\%). Of those who are testing their smoke alarms, three quarters are not doing so within the recommended minimum monthly time frame. This reflects either a degree of confusion about how often testing is required, or a complacency about the importance of this routine. Poor adherence to the recommended testing schedule also increases the chance that smoke alarms might not be in working order. Sharp and Carter found that respondents who said they had checked their detectors to see if they worked were significantly more likely to have functional smoke detectors [9].

There was also a small percentage of occupants who reported testing methods that could be dangerous. Examples included burning paper underneath the smoke alarm, or using matches or lighters. These testing methods are considered hazardous for obvious reasons. The majority of occupants who test their alarms knew to press the button $(77.7 \%)$. Artificial smoke was reportedly used in only one case.

\section{Cleaning}

Despite the fact that smoke alarms should be cleaned once a year with a vacuum cleaner (to remove particles that might affect smoke alarm performance) only one in four occupants who own a smoke alarm report carrying out any cleaning of the unit (Table 3). The majority of participants appear not to have any knowledge that the alarm should be cleaned. When occupants were asked if they clean their alarm a common response was "I didn't know you had to clean it". In addition, of those that did report cleaning their alarms, only a small percentage reported cleaning their alarm correctly, by vacuuming (15\%). Instead, over half said they dusting or wiping the outside of the alarm which is unlikely to protect the smoke alarm's functional status. 


\section{Occupant Characteristics}

Examination of the frequencies across the different demographic groups showed that the numbers of people who reported never changing their smoke alarm battery (Table 4; approximately 17 to $20 \%$ ) is very closely related to the number of non-functional alarms that are reported in random tests [7, 8, 9]. A higher proportion was noted for unemployed people ( $28 \% ; 11$ of 39$)$ and students (33\%; 6 of 18). Results for the unemployed are in keeping with previous research which reported that households with lower income are less likely to own smoke alarms [12]. In this case, it may be seen to extend to difficulty in paying for expensive 9V lithium batteries. For students this may have occurred because they are more likely to be living at home with their parents, or in group housing. Responsibility for smoke alarm maintenance may then be deferred to the head of the household (a parent or other authority figure).

A similar pattern emerged for testing of smoke alarms (Table 5), with the highest proportions of people stating that they never test them coming from the unemployed (47\%; 18 of 34$)$ and students $(43 \% ; 6$ of 14). It is important to recognise however that even though a slightly greater percentage of students and unemployed persons are not testing their alarms, when examining each group separately (the retired alone or the employed for example) the percentage of persons who never test their alarms make up the largest proportion within all groups. Similarly, within each group (regardless of employment status) the largest proportions of occupants are not cleaning their alarms (Table 6). This finding indicates that there is no one specific group within society that requires more information on correct smoke alarm testing and cleaning procedures, but rather the community as a whole should be targeted.

In terms of education level results showed that the percentage of persons reportedly not changing their smoke alarm batteries, testing, or carrying out cleaning was fairly consistent across all groups, with the exception of apprentices (only one person of 14 reported never changing batteries in their alarm). This was only a small group, and so it would not be appropriate to draw conclusions specifically about apprentices here.

To summarise, results indicate that apart from students (who might not be head of household and are living with their parents) the unemployed showed a higher percentage of occupants reported they do not change their alarm batteries, compared to the employed and those not in the labour force. Hence, support measures could be targeted at this group, particularly if the unemployed are unable to cover the cost of replacing alarm batteries on a yearly basis. However, when considering smoke alarm testing and cleaning maintenance procedures, there is no one group in particular that needs to be targeted, rather there is a need for the community as a whole to be educated in relation to the correct maintenance practices.

\section{Future Research}

The current study found that a number of people are not aware that hard wired detectors require battery replacements. Perhaps in future alarm ownership studies it would be beneficial to ask a question whether hardwired smoke alarms require battery changes or testing to uncover further the true understanding people have of such devices. This is particularly important to know as more new houses are being installed with hardwired devices.

In addition, future research could also test occupant knowledge regarding the maximum 10 year lifespan that applies to most smoke alarms, which could then also be compared to the reported age of their current alarm.

\section{CONCLUSIONS}

Results from this study show that although a high percentage of occupants reportedly own smoke alarms, over one third of owners are not testing their alarms. Even when testing does occur, three quarters of people reported not doing so regularly enough. At least seventeen percent of those occupants who own alarms never carry out battery changes. Results indicate that occupants with hardwired alarms may not be aware that although the alarm has a direct power supply from their homes, the battery still may need replacing on a regular basis. Despite the fact that smoke alarms should be cleaned once a year with a vacuum cleaner only one quarter of occupants who own an alarm clean the alarm and even less use a vacuum cleaner. Due to overall poor maintenance procedures in regards to testing the alarm, battery changes, and cleaning the 
alarm, the number of units that are functional may be a great deal less that the number of alarms reported to be owned by occupants.

\section{REFERENCES}

[1] McKnight, R.H., Struttmann, T.W., and Mays, J.R., (1995) Finding homes without smoke detectors: One step in planning burn prevention programs, The Journal of Burn Care and Rehabilitation 16(5): 548-556, http://dx.doi.org/http://dx.doi.org/10.1097/00004630-199509000$\underline{00016 .}$.

[2] New South Wales Government, Department of Planning, "New smoke alarm requirements for existing buildings from May 1st 2006," New South Wales Government, Sydney, 2006.

[3] Metropolitan Fire Brigade (2004). Smoke alarm information brochure. Retrieved March 5, 2006 from: http://www.mfb.org.au/asset/PDF/smoke\%20alarm\%20brochure.pdf

[4] Queensland Fire and Rescue Service, (2006). New smoke alarm legislation fact sheet. Retrieved March 17, 2011 from http://www.fire.qld.gov.au/communitysafety/smokealarms/legislation.asp

[5] Australasian Fire Authorities Council (2006). Position on smoke alarms in residential accommodation. Retrieved September 18, 2007, from www.afac.com.au

[6] Center for Disease Control, (1986) Prevalence of smoke detectors in private residences - DeKalb County, Georgia, 1985, Morbidity and Mortality Weekly Report 35(28): 445-448.

[7] Neily, M.L., Smith, C.L., and Shapiro, J.I. (1994). Residential smoke detector performance in the United States, International Journal for Consumer Safety 1 (1): 43-50.

[8] Douglas, M.R., Mallonee, S., and Istre, G.R. (1999). Estimating the proportion of homes with functioning smoke alarms: A comparison of telephone survey and household survey results, American Journal of Public Health 89(7): 1112-1114, http://dx.doi.org/10.2105/AJPH.89.7.1112

[9] Sharp, G.B., and Carter, M.A. (1992). Prevalence of smoke detectors and safe tap water temperatures among welfare recipients in Memphis, Tennessee, Journal of Community Health 17(6): 351-365, http://dx.doi.org/10.1007/BF01323997

[10] McLoughlin, E., Marchone, M., Hanger, S. L., German, P.S. and Baker, S.P., (1985) Smoke detector legislation: Its effect on owner occupied homes, American Journal of Public Health 75(8): 858-862, http://dx.doi.org/http://dx.doi.org/10.2105/AJPH.75.8.858.

[11] Mickalide, A., and Validzic A. (1999). Smoke alarm maintenance in low-income families, American Journal of Public Health 89(10): 1584- 1585, http://dx.doi.org/10.2105/AJPH.89.10.1584

[12] Shults R.A., Sacks, J.J., Briske, L.A., Dickey, P.H., Kinde, M.R., Mallonee, S., and Douglas, M.R. (1998). Evaluation of three smoke detector promotion programs, American Journal of Preventative Medicine 15(3): 165-171, http://dx.doi.org/10.1016/S0749-3797(98)00071-3

[13] Ahrens, M., "U.S. experience with smoke alarms and other fire detection/ alarm equipment," Fire Analysis and Research Division, National Fire Protection Association, Quincy, MA, 2006.

[14] NFPA, (2008). Smoke Alarms, Facts \& figures. Retrieved March 17, 2011 from http://www.nfpa.org/categoryList.asp?categoryID=278\&URL=Research\%20\&\%20Reports/Fact\% 20sheets/Smoke\%20alarms

[15] Australian Bureau of Statistics, "Household Safety, New South Wales," Australian Bureau of Statistics, 4378.1, Australia, 1998. 